\title{
Gaz Atomizasyon Yöntemi ile AZ31 Mg Tozu Üretiminde Gaz Basıncının Etkisinin Araştırılması
}

\author{
Investigation of the Effect of Gas Pressure on AZ31 Mg Powder Production by Gas \\ Atomization Method
}

\author{
Mehmet AKKAŞ*1,a, Kamal Mohamed EM AKRA ${ }^{2, b}$, Tayfun ÇETİN ${ }^{2, c}$, Mustafa BOZ ${ }^{2, d}$ \\ ${ }^{1}$ Kastamonu Üniversitesi, Mühendislik ve Mimarlık Fakültesi, Makine Mühendisliği Bölümü, 37150, Kastamonu \\ ${ }^{2}$ Karabük Üniversitesi, Teknoloji Fakültesi, Imalat Mühendisliği Bölümü, 78050, Karabük
}

\author{
• Geliş tarihi / Received: 10.01.2018 • • Düzeltilerek geliş tarihi / Received in revised form: 18.07.2018 • Kabul tarihi / Accepted: 07.08 .2018
}

\begin{abstract}
$\ddot{O} \mathbf{z}$
$\mathrm{Bu}$ çalışmada, gaz atomizasyonu yöntemi ile üretilen $\mathrm{AZ3} 1 \mathrm{Mg}$ alaşımı tozunun şekli ve boyutu üzerine gaz basıncının etkisi deneysel olarak araştırılmıştır. Deneyler $790{ }^{\circ} \mathrm{C}$ sabit sıcaklıkta, $2 \mathrm{~mm}$ nozul çapında ve 4 farklı gaz basıncı $(5,15$, 25 ve 35 bar) uygulanarak yapılmıştır. Ergiyiğin atomize işlemi argon gazı ile yapılmıştır. Üretilen AZ31 Mg tozunun şeklini belirleyebilmek için taramalı elektron mikroskobu (SEM), üretilen tozların iç-yapılarında oluşan fazları ve bu fazların \% oranlarını belirleyebilmek için XRD ve XRF analizi, toz boyut analizi için ise lazer ölçüm cihazı kullanılmıştır. Üretilen AZ31 Mg alaşım tozlarının genel görünümlerinin ligament, çubuksu, damlamsı, flake (pul) ve küresel şeklinde olduğu, gaz basıncının artmasına bağlı olarak tozların şeklinin çoğunlukla flake ve küresel'e doğru değiştiği görülmüsştür. Elde edilen en ince tozun $790{ }^{\circ} \mathrm{C}$ sıcaklıkta, $2 \mathrm{~mm}$ nozul çapında 35 bar gaz basıncında oluştuğu ve tozların genelinin damlamsı ve küresel şekilli olduğu tespit edilmiştir.
\end{abstract}

Anahtar kelimeler: AZ31 Mg alaşım tozu, Gaz atomizasyonu, Gaz basıncı

\begin{abstract}
In this study, the effect of gas pressure on the shape and size of the AZ31Mg alloy powder produced by the gas atomization method is investigated experimentally. Experiments were carried out at a constant temperature of $790{ }^{\circ} \mathrm{C}$, with a diameter of $2 \mathrm{~mm}$ and by applying 4 different gas pressures $(5,15,25$ and $35 \mathrm{bar})$. The atomization of the melt is carried out with argon gas. Scanning electron microscopy (SEM) was used to determine the shape of the AZ31 Mg powder produced, XRD and XRF analyzes were used to determine the phases generated in the internal structures of the powders produced and percentage of these phases, and laser measurement device was used for powder size analysis. The general appearance of the AZ31 Mg alloy powders produced is in the form of ligaments, rods, droplet, flakes and spherical, and the shape of the powders has mostly changed to flake and spherical depending on the increase of the gas pressure. It was determined that the finest powder obtained was at a temperature of $790{ }^{\circ} \mathrm{C}$, a gas pressure of 35 bar at a diameter of $2 \mathrm{~mm}$, and that the overall powder was droplet and spherical.
\end{abstract}

Keywords: AZ31 Mg alloy powder, Gas atomization, Gas pressure

\footnotetext{
*a Mehmet AKKAŞ; mehmetakkas@kastamonu.edu.tr; Tel: (0366) 871 85 56-112; orcid.org/0000-0002-0359-5142

${ }^{b}$ orcid.org/0000-0003-0992-7753 $\quad{ }^{c}$ orcid.org/0000-0001-8060-344X $\quad$ orcid.org/0000-0001-9148-0748
} 


\section{Giriş}

Yüksek özgül mukavemet ve hafiflik avantajlarından dolayı magnezyum alaşımları savunma sanayi ve taşımacılık sektöründe son derece önemlidir (Mordike ve Ebert, 2001). Magnezyum ve alaşımları ayrıca yüksek 1sıl iletkenlik, yüksek boyutsal kararlılık, iyi elektromanyetik koruma, yüksek sönümleme, iyi işlenebilirlik ve geri kolay geri dönüşüm özelliklerine sahiptir (Froes vd., 1998; Fredrich ve Schumann, 2001; Furuya vd., 2001). Bu gibi avantajlarından dolayı $\mathrm{Mg}$ alaşımları otomotiv, havacilık, bilgisayar, spor malzemeleri, mobil telefonlar gibi farklı sektörlerde değeri her geçen gün artmaktadır. Bunun yanısıra düşük ağırlık ve metabolizma uyumu açısından implant malzemesi olarak da kullanımı yaygınlaşmaya başlamıştır (Gray ve Luan, 2002; Duygulu vd., 2007; Kaya, 2007; Kaya vd., 2007). Magnezyum alaşımsız olarak düşük mukavemet ve tokluk değerlerine sahip olduğundan alaşımlandırılarak kullanılmaktadır. $\mathrm{Bu}$ nedenle, magnezyumun mukavemetini, korozyonu ve yangın direncini arttırmak için, genellikle alüminyum, çinko, zirkonyum ve nadir toprak elementleri gibi elementlerle alaşımlandırılırlar (Neite vd., 1996; Karagöz vd., 2009). Alaşımlandırma yapılan malzemelerde dayanım artıracağından, magnezyum gibi şekillendirilebilirliği düşük malzemelerin ve alaşımlarının toz metalürjisi ile üretimi ihtiyaç haline gelmiştir.

Toz metalürjisi yöntemi ile kompozitler elde edilerek malzemelere yüksek sıcaklıkta yüzey aşınma direnci, yüzey sürtünmesi ve yüzey gerilmelerinin arttırılması gibi özellikler kazandırılabilir. Toz metalürjisi yöntemiyle toz üretme tekniği 4 farklı yöntemle yapılır. Bunlar; mekanik yöntemler, kimyasal yöntemler, elektroliz yöntemi ve atomizasyon yöntemidir. $\mathrm{Bu}$ üretim yöntemleri içerisinde ince ve küresel tozlar elde etmek için en yaygın olarak gaz atomizasyon yöntemi kullanılır. Küresel toz arzulanmasının en önemli sebebi, presleme ve sinterleme aşamalarında toz-toz temasının homojen ve çok yönlü olması gerektiğinden istenmektedir (Oğuz vd., 2011).

Atomizasyon, ergitilmiş metalin su, hava ve gaz basıncı ile veya mekanik olarak çok küçük damlacıklara parçalanması ve katılaşması olarak tanımlanır. Bu yüzden atomizasyon işlemi, su atomizasyonu, gaz atomizasyonu, santrifüj atomizasyonu ve vakum atomizasyonu olmak üzere 4 farklı bölüme ayrılır. Fakat üretilen metal ve metal dışı tozların yarısından fazlasının gaz atomizasyonu ile üretilmesi bu yöntemi üstün k1lmaktadır. Gaz atomizasyonunda siv1 metal demetini parçalamak için basınçlı akışkan olarak hava, azot, argon ve helyum gibi gazlar kullanılabilir (Yıldırım ve Özyürek, 2013; Gökçe vd., 2017). Gerçekte, gaz atomizasyon yöntemiyle ergitilebilen her türlü metal ve alaşım tozlarının üretimini gerçekleştirmek mümkündür.

Gaz atomizasyon yöntemiyle toz üretiminde; gazın cinsi, gaz basıncı, nozul çapı ve ergitme sicaklığı gibi parametreler kullanılır. Gaz basıncının artmasıyla, ergitilmiş malzemenin sıcaklığı ve viskozitesi düşer bu da daha küçük boyutta toz üretilmesini mümkün kılar.

$\mathrm{Bu}$ çalışmada, üretilen tozların preslenebilirliğini ve sinterlenebilirliğini artırabilmek için küçük ve küresel tozlar üretilmeye çalışılmıştır. Bu amaçla, otomotiv ve havacilık endüstrisinde yaygın kullanımı olan AZ31 Mg alaşımının gaz atomizasyonu yöntemi ile toz üretimi gerçekleştirilmiştir.

\section{Deneysel Çalışmalar}

Deneysel çalışmalar Karabük Üniversitesi Teknoloji Fakültesi İmalat Mühendisliği Bölümü Laboratuvarında bulunan Gaz Atomizasyon Ünitesi'nde yapılmıştır. Şekil 1'de görülen Gaz Atomizasyon Ünitesi yedi temel bölümden oluşmaktadır.

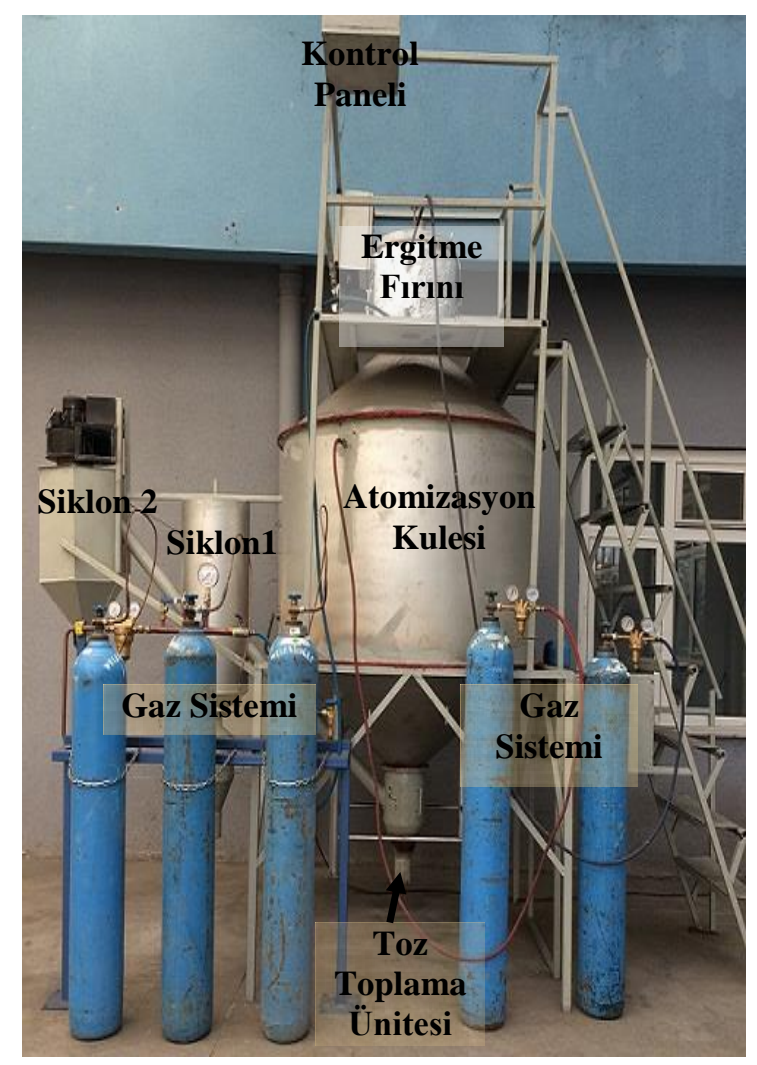

Şekil 1. Gaz Atomizasyon Ünitesi 
Bunlar; Ergitme fırını (yaklaşık olarak $1200{ }^{\circ} \mathrm{C}$ 'de sürekli çalışabilir), Atomizasyon kulesi (paslanmaz çelikten imal edilmiştir), Nozul ve nozul tutucu (yakından eşlemeli ve dairesel delikli süpersonik), Toz toplama ünitesi, Gaz basınç rampas1, Siklonlar ve Kontrol paneli. Kullanılan AZ31 Mg alaşımı külçe halinde Varzene Metal şirketinden temin edilmiştir.

Deneyler $790{ }^{\circ} \mathrm{C}$ sabit sicaklıkta, $2 \mathrm{~mm}$ nozul çap1 ve 4 farklı gaz basıncı $(5,15,25$ ve 35 Bar) uygulanarak yapılmıştır. Atomizasyon gazı olarak argon gazı kullanılmışıır.

Toz boyut analizleri, Bartın Üniversitesi Merkezi Araştırma Laboratuvarında bulunan Mastersizer 3000 model cihaz ile yapılmıştır. Cihazın çalışma prensibi, numune üzerine kırmızı ve mavi lazer 1şığı gönderilir. Numuneden yansıyan ve kırılan lazer 1 şı̆̆g detektörler ile incelenir. Saçılan 1şığın açısı ve şiddeti numunenin parçacık boyut dağglımını belirler.

Üretilen AZ31 Mg alaşım tozlarının boyut değerleri $\operatorname{Dv}(10)$, Dv(50) ve $\operatorname{Dv}(90)$ olarak Tablo 1 'de verilmiştir. Bunun yanısıra Şekil 2'de ise gaz basıncının toz boyutuna etkisi net bir şekilde görülmektedir.

Gaz atomizasyon yöntemiyle toz üretiminde gaz basıncının toz boyutu ve şekli üzerinde önemli bir etkiye sahip olduğu bilinmektedir. Tablo 1'de görüldüğü gibi bu çalışmada en yüksek gaz basıncı değeri 35 bar olarak alınmıştır.

Tablo 1. AZ31 Mg tozlarının boyut değerleri

\begin{tabular}{|l|l|l|l|l|l|l|}
\hline $\begin{array}{l}\text { Sıcaklık } \\
\left({ }^{(} \mathbf{C}\right)\end{array}$ & $\begin{array}{l}\text { Nozul Çapı } \\
(\mathbf{m m})\end{array}$ & $\begin{array}{l}\text { Gaz Basıncı } \\
(\mathbf{b a r})\end{array}$ & Dv (10) $\boldsymbol{\mu m}$ & Dv (50) $\boldsymbol{\mu m}$ & Dv (90) $\boldsymbol{\mu m}$ & $\begin{array}{l}\text { Spesifik } \\
\text { Yüzey Alanı } \\
\left(\mathbf{m}^{2} / \mathbf{k g}\right)\end{array}$ \\
\hline \multirow{3}{*}{$\mathbf{7 9 0}$} & \multirow{2}{*}{2} & 5 & 100 & 383 & 984 & 27.89 \\
\hline & 15 & 54 & 144 & 402 & 57.31 \\
\hline & 25 & 28.1 & 94 & 263 & 127.8 \\
\cline { 2 - 7 } & 35 & 24.5 & 66 & 146 & 117.8 \\
\hline
\end{tabular}

Tablo 1 ve Şekil 2 incelendiğinde, üretilen tozların 0.1 ile $984 \mu \mathrm{m}$ aralığında olduğu ve en küçük ortalama toz boyutunun $66 \mu \mathrm{m}$ olarak 35 bar gaz basıncında elde edildiği görülmektedir. 35 bar gaz basincinda üretilen tozların \%10'u 24.5 $\mu \mathrm{m}$ alt1 iken, \%90'1 ise $146 \mu \mathrm{m}$ altı tozlardan oluşmuştur. Üretilen tozların en az \%10'unun ise $10 \mu \mathrm{m}$ altı tozlardan oluştuğu tespit edilmiştir, ancak bu tozlar gerek atomizasyon kulesi ve siklonlara gerekse tozların depolandığı kaplara sıvandığı için ölçümü mümkün olmamıştır.

Literatürde kg başına alan olarak bilinen Spesifik Yüzey Alanı incelendiğinde, gaz basıncının artmasıyla spesifik yüzey alanının arttı̆̆1 görülmektedir. Spesifik yüzey alanı hesabı:

\section{S=6/PM.D denkleminden çıkarılmaktadır.}

Burada; S: Spesifik yüzey alan1, PM: teorik malzeme yoğunluğu, D: ortalama parçacık boyutu olarak tanımlanır.

Spesifik yüzey alanı üretilen tozların preslenebilirlik ve sinterlenebilirlik özelliklerini etkilediği bilinmektedir.

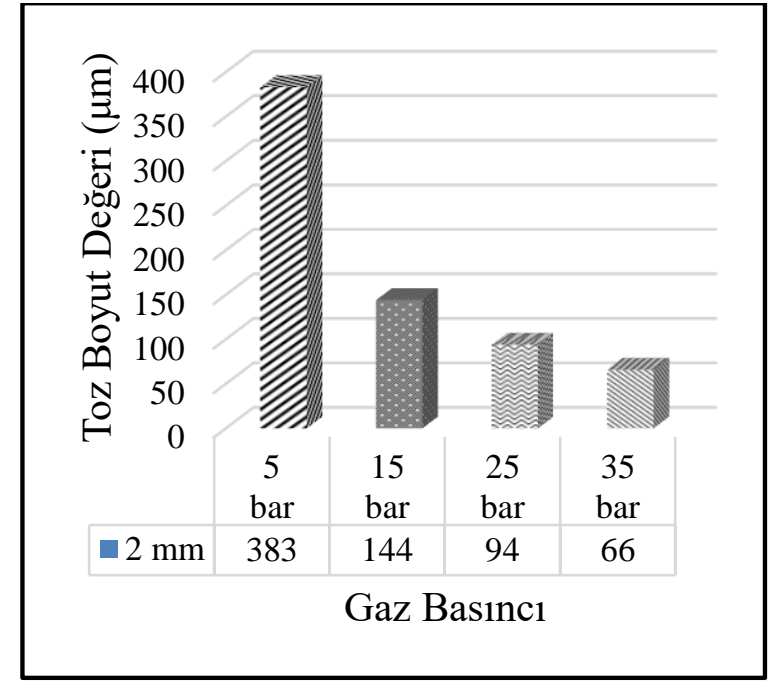

Şekil 2. Farklı gaz basınçlarında üretilen

Gaz atomizasyonu yöntemi ile AZ31 Mg tozu üretiminde yapılan deneyler sonucunda, gaz basıncının etkisi açıkça görülmüş̧ür. Bunun yanısıra gaz atomizasyonu yöntemi ile toz üretiminde atomizasyon sicaklığının ve nozul çapının da etkisi vardır. Fakat gaz atomizasyonu ile toz üretiminden önemli parametre atomizasyon gazı basıncı olduğu düşünülmektedir. 
Gaz basıncının arması ile üretilen tozların tane boyutunun küçüldüğü Şekil 2'de verilen toz boyut değerlerinde açıkça anlaşılmaktadır.

AZ31 Mg tozlarının boyut değerleri. Şekil 2 incelendiğinde gaz basıncının artmasına bağlı olarak ortalama toz boyutunun küçüldüğü görülmektedir. 5 bar gaz basincında üretilen tozun ortalama toz boyutu (Dv50) $383 \mu \mathrm{m}$ iken, gaz basınc 35 bar'a artırıldığında ortalama toz boyutu (Dv50) $66 \mu$ m'a kadar küçülmüştür.
$\mathrm{Bu}$ çalışmada farklı gaz basınçlarında üretilen tozlardan alınan SEM görüntüleri (100X) Şekil 3 'te verilmiştir.

Şekil 3'ten görüldüğü gibi gaz basıncının artması ile toz boyutu küçülmektedir. Gaz basıncına bağlı olarak toz boyutundaki küçülmenin sebebi, yüksek gaz basınçlarında ergiyik metale daha yüksek enerji aktarılması sağlandığ 1 için metal tozu üretiminde ortalama toz boyut değerinin küçüldüğü olarak yorumlanabilir.
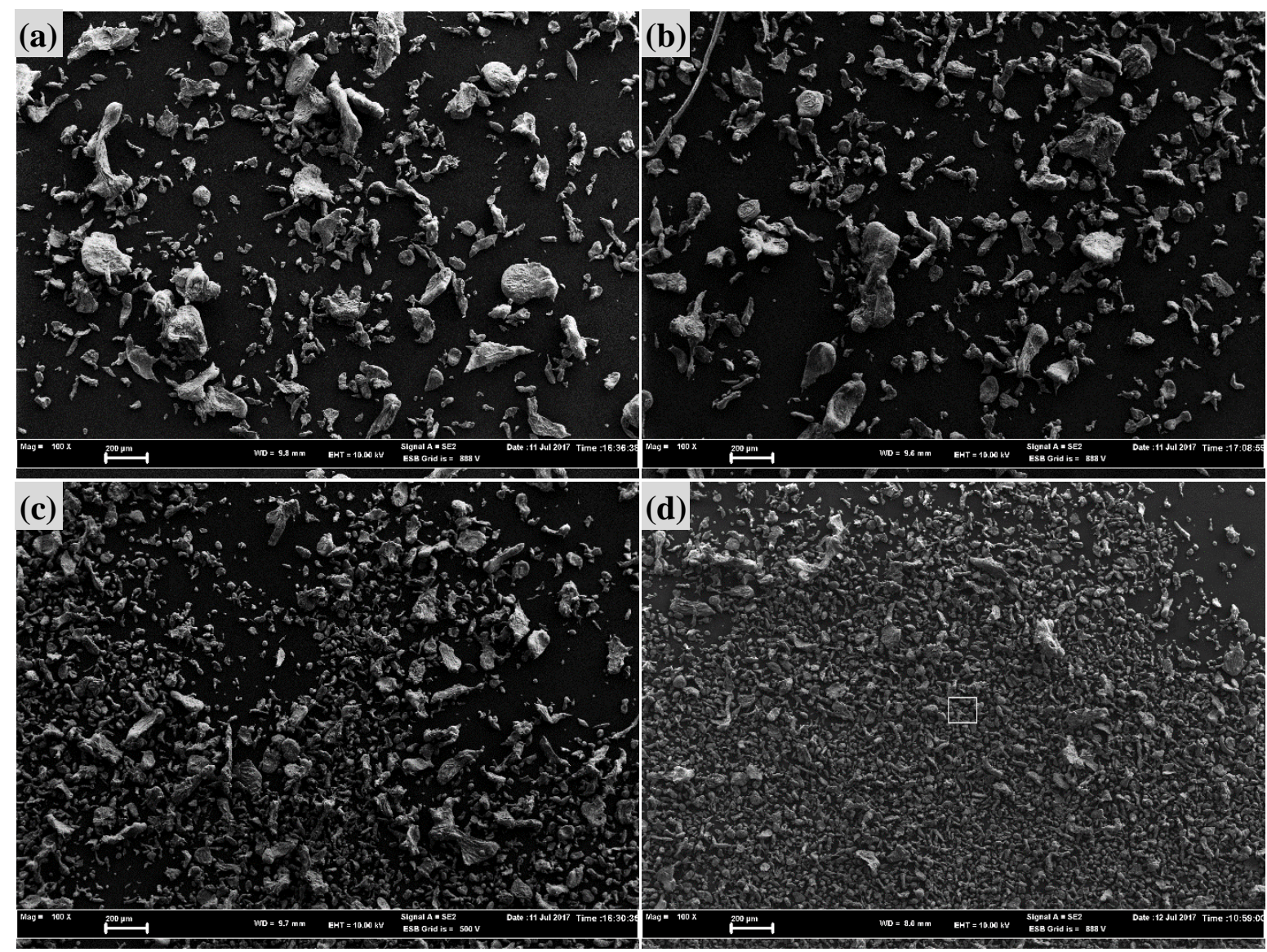

Şekil 3. Farklı gaz basınçlarında a) 5 bar b) 15 bar c) 25 bar d) 35 bar üretilen tozların SEM görüntüleri (100X).

Üretilen tozların genellikle karmaşık, ligamet, yapraksı, damlamsı ve küresel şekilde olduğu Şekil 4' den anlaşılmaktadır.

Şekil 4'de verilen SEM görüntülerinden gaz basıncının artmasına bağlı olarak toz şeklinin ligament, çubuksu ve karmaşı şekilden, damlamsı ve küresel'e doğru değiştiği görülmektedir. Özellikle 35 bar gaz basincında üretilen ve Şekil 4'de SEM görüntüsü verilen tozların ciddi anlamda küçüldüğü, şeklinin ise damlamsı ve küresel olduğu belirgin bir şekilde görülmektedir.

Şekil 4 a ve b incelendiğinde tozların ligament ve karmaşık şekilli olduğu görülmektedir. Bunun en önemli sebebinin atomizasyon gaz basıncinın düşük olması ve atomizasyon kulesinin yeterli yükseklikte olmaması olarak düşünülmektedir. Zira toz partikülleri küreselleșebilecek zamanı bulamadan atomizasyon kulesinin tabanına çarparak katılaşmaktadırlar. 
Preslenebilirlik ve sinterlenebilirlik açısından toztoz teması olduğu için genellikle küresel toz arzu edilmektedir. Bu yüzden, bu çalışmada amacımız genellikle küresel toz üretimi olmuştur. Kürese tozların dışındaki tozlar da farklı üretim yöntemlerinde (filtre yapımında) kullanılabilir.
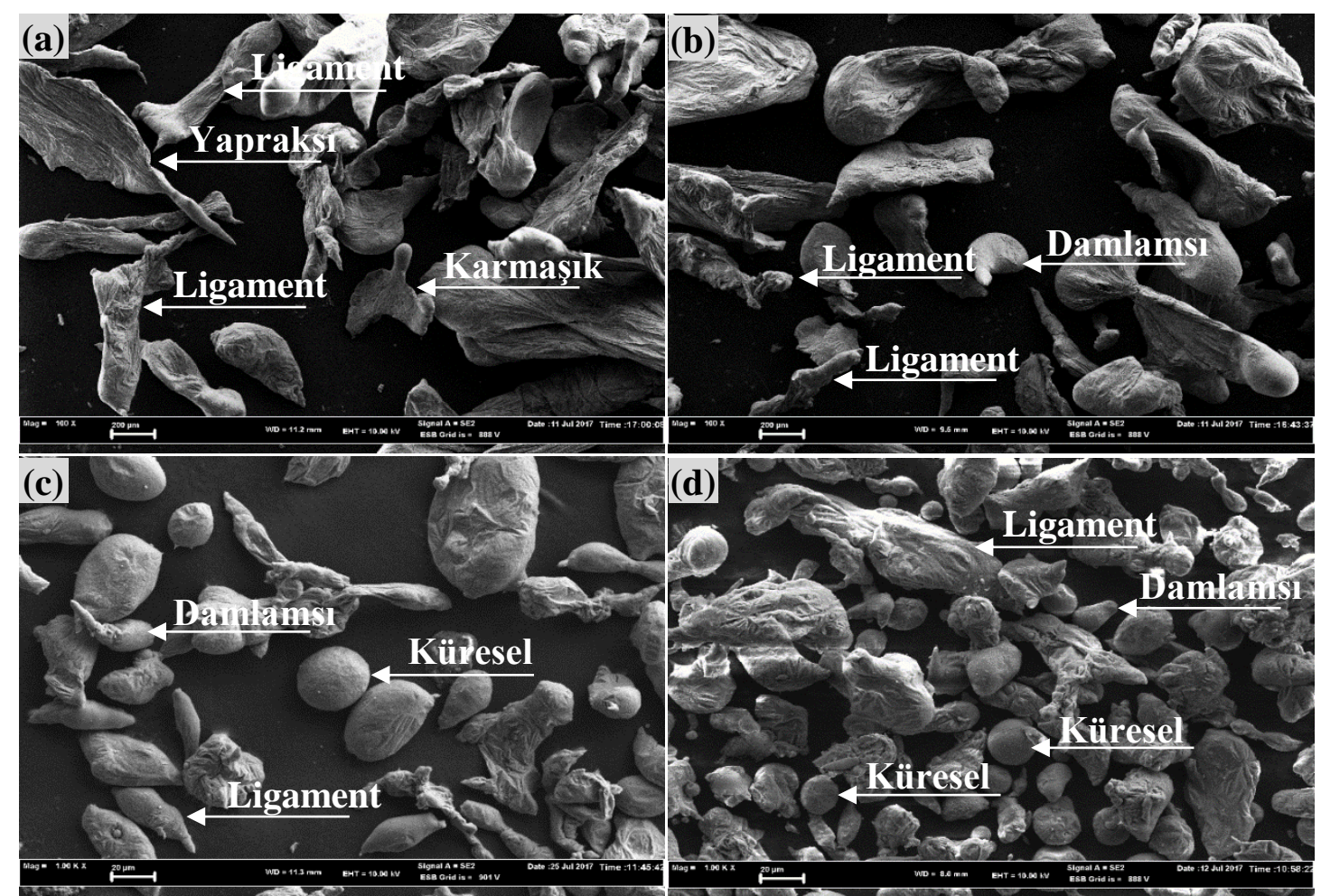

Şekil 4. Farklı gaz basınçlarında a) 5 bar b) 15 bar c) 25 bar d) 35 bar üretilen tozların SEM görüntüleri (1000X).

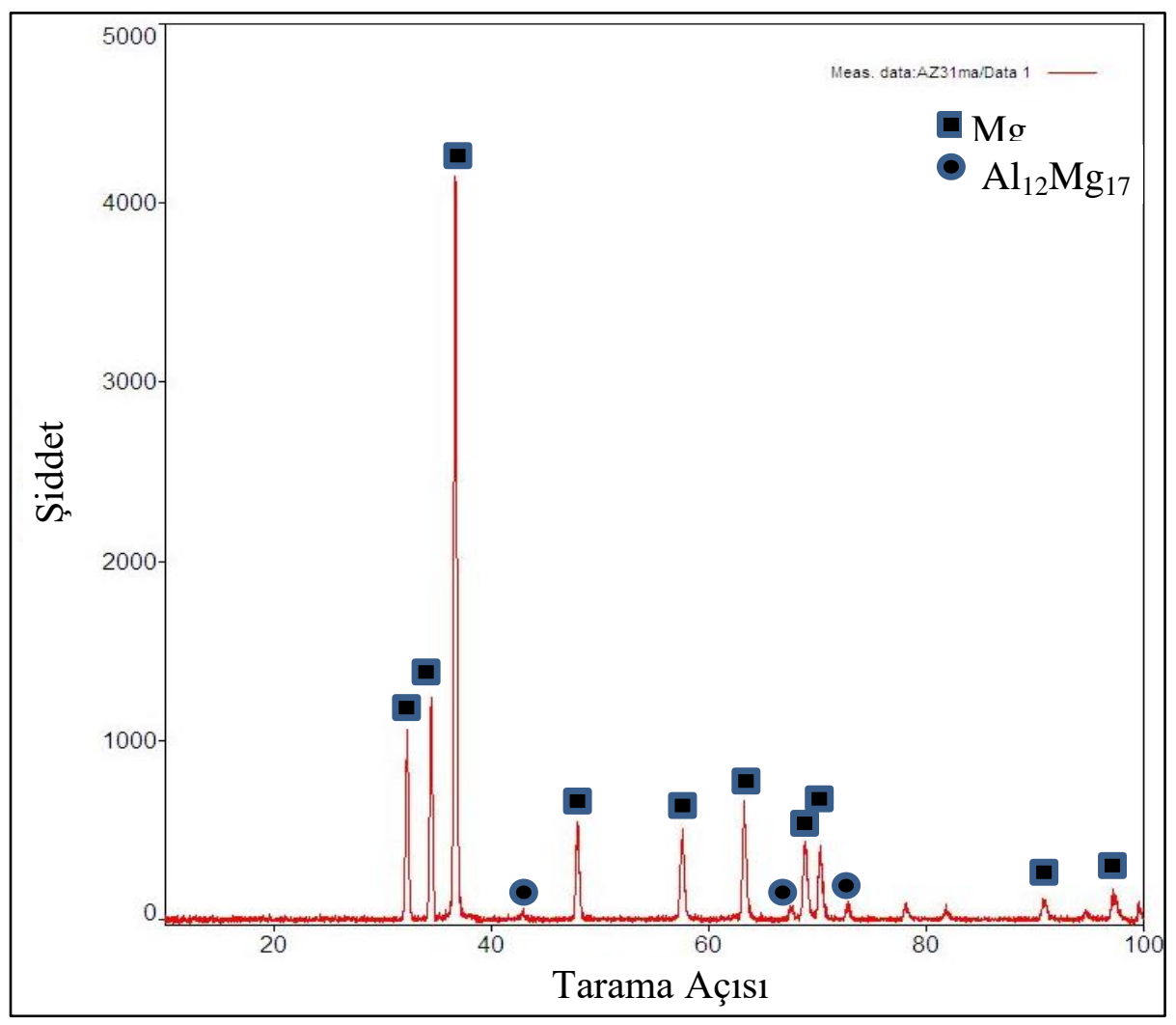

Şekil 5. Üretilen AZ31 Mg alaşım tozunun XRD grafiğgi. 
Üretilen magnezyum alaşımı AZ31 Mg tozunun XRD grafiğinde (Şekil 5), $\alpha(\mathrm{Mg})$ ve $\beta\left(\mathrm{Al}_{12} \mathrm{Mg}_{17}\right)$ fazları tespit edilmiştir. Şekil 5'de verilen XRD grafiği sonucunda $\mathrm{Mg}$ ve $\mathrm{Al}$ elementlerinin katılaşma boyunca $\mathrm{Al}_{12} \mathrm{Mg}_{17}$ bileşiğini oluşturduğu yorumlanmaktadır. Bunun yanısıra üretilen tozların kimyasal analizini belirleyebilmek amacıyla XRF analizi yapılmıştır. Analiz sonuçları Tablo 2'de verilmiştir.

Tablo 2. Üretilen AZ31 Mg alaşım tozunun XRF analiz sonucu.

\begin{tabular}{|l|l|l|l|l|l|}
\hline Element & Mg & Al & Zn & Mn & Si \\
\hline $\begin{array}{l}\text { İcerik } \\
\text { (Ăğırlık } \\
\text { \%) }\end{array}$ & 94.71 & 2.75 & 1.62 & 0.61 & 0.22 \\
\hline
\end{tabular}

Tablo 2'de verilen sonuçlar doğrultusunda, üretilen $\mathrm{AZ31} \mathrm{Mg}$ alaşım tozunun kimyasal analizi \%94.71 Mg, \%2.75 Al, \%1.62 Zn. \%0.61 $\mathrm{Mn}$ ve $\% 0.22 \mathrm{Si}$ içermektedir. Çünkü geçmişte yaptığımız çalışmalarda gaz atomizasyonu ile toz üretiminin en büyük avantaj1 üretilen toz ile hammadde arasında kimyasal bileşimin neredeyse değişmediğini tespit ettik. $\mathrm{Bu}$ yüzden diğer parametrelerin kimyasal analizine gerek duymadık. Mn içeriğinin fazla olması ise atomizasyon kulesinin çok iyi temizlenmemiş olması ve daha önce yapılan üretimlerden kaldığını yorumlayabiliriz.

Üretilen tozlar toz toplama ünitesinden alınırken oksijen ile teması kesmek neredeyse imkânsız bizim için. Ancak yaptığımız farklı çalışmalarda ürettiğimiz tozların preslenebilirliğini ve sinterlenebilirliğini çalıştığımızda çok az miktarda oksijen olduğu tespit edilmiştir. $\mathrm{Bu}$ yüzden bu çalışmada oksijen değerlendirmesi yapmadık.

\section{Sonuçlar}

Farklı parametreler uygulanarak gaz atomizasyon yöntemi ile üretilen $\mathrm{AZ31} \mathrm{Mg}$ tozunun karakterizasyonu üzerine yapılan bu çalışmada aşağıdaki sonuçlar elde edilmiştir.

1. Gaz atomizasyon yöntemi ile farklı boyut ve şekilde tozlar üretilmiştir. En küçük toz boyut değeri $790{ }^{\circ} \mathrm{C}$ sıcaklık, $2 \mathrm{~mm}$ nozul çapı ve 35 bar gaz basıncında elde edilmiştir.

2. Artan gaz basıncına bağlı olarak toz boyut değerlerinin düştüğü tespit edilmiştir.

3. Gaz basıncinın artması ile, üretilen tozların şekilleri ligament, pulsu ve karmaşık yapıdan damlamsı ve küresel yapıya doğru değiştiği gözlemlenmiştir.

4. Üretilen $A Z 31 \mathrm{Mg}$ alaşım tozunun XRD ve XRF analizleri sonucunda iç yapıda $\alpha$ ve $\beta$ (Mg17A112) fazları tespit edilmiştir.

\section{Teșekkür}

$\mathrm{Bu}$ çalı̧̧ma Karabük Üniversitesi Teknoloji Fakültesi İmalat Mühendisliği Bölümü Laboratuvarında bulunan Gaz Atomizasyon Ünitesi'nde yapılmıştır.

\section{Kaynaklar}

Duygulu, O., Kaya, R.A., Oktay, G. and Kaya, A.A., 2007. Investigation on the Potential of Magnesium Alloy AZ31 as a Bone Implant, Materials Science Forum, 546-549, 421-424.

Fredrich, H. and Schumann, S., 2001. Research for a New Age of Magnesium in the Automotive Industry, J. Mat. Proc. Tech., 117, 276-28.

Froes, F.H., Eliezer, D. and Aghion, E., 1998. The Science, Technology, and Applications of Magnesium. J. Mat. Proc. Tech., 50 (9), 30-34.

Furuya, H., Kogiso, N., Matunaga, S. and Senda, K., 2001. Applications of Magnesium Alloys for Aerospace Structure Systems, Materials Science Forum, 341-348.

Gökçe, A., Findık, F., ve Kurt, A.O., 2017. Alüminyum ve Alaşımlarının Toz Metalurjisi İşlemleri. Engineer \& the Machinery Magazine, 58, 686.

Gray, J.E. and Luan, B., 2002. Protective Coatings on Magnesium and its Alloys-A Critical Review, J. Alloys Compd., 336, 88-113.

Karagöz, Ş., Yamanoğlu, R., ve Atapek, Ş.H., 2009. Metalik toz işleme teknolojisi ve prosesleme kademeleri açısından parametrik ilişkiler, Eskişehir Osmangazi Üniversitesi Mühendislik Mimarlık Fakültesi Dergisi, Cilt:XXII, Sayı:3, $77-87$.

Kaya, A.A., 2007. Future of Magnesium: Applications in Transportation and Bone Surgery, 10th Int. Symposium on Advanced Materials (ISAM2007), Islamabad, Pakistan.

Kaya, A.A., Kaya, R.A., Witte, F., and Duygulu, Ö., 2007. Useful Corrosion- Potential of Magnesium Alloys as Implants, International Corrosion Engineering Conference, Seoul, Korea.

Mordike, B.L., Ebert, T., 2001. Magnesium PropertiesApplications-Potential, Mat. Sci. Eng. A, 302, 37-45. 
Neite, G., Kubota, K., Higashi, K. and Hehmann, F., 1996. Chapter 4-Magnesium-Based alloys, in: R.W. Cahn, P. Haasen, E.J. Kramer (Eds.), Structure and Properties of Nonferrous Alloys, vol. 8, 113-212.

Oğuz, Ş., Öztürk, Z., Uzun, E., Kurt, A. ve Boz, M., 2011. Gaz atomizasyonu yöntemi ile kalay tozu üretiminde gaz basıncının toz boyutu ve şekline etkisi. 6th International Advanced Technologies Symposium (IATS'11), 565-568.

Yıldırım, M., and Özyürek, D., 2013. The effects of $\mathrm{Mg}$ amount on the microstructure and mechanical properties of Al-Si-Mg alloys, Materials \& Design, 51, 767-774. 